Arch Virol (2000) 145: 1725-1732

Archives of
Virology
$\substack{\text { OSpringer-Verlag } 2000 \\ \text { Printed in Austria }}$

\title{
Oral immunogenicity of the plant derived spike protein from swine-transmissible gastroenteritis coronavirus
}

\author{
Brief Report \\ N. Gómez ${ }^{1}$, A. Wigdorovitz ${ }^{2}$, S. Castañón ${ }^{3}$, F. Gil ${ }^{1}$, R. Ordás ${ }^{3}$, \\ M. V. Borca $^{2}$, and J. M. Escribano ${ }^{1}$ \\ ${ }^{1}$ Departamento de Mejora Genética y Biotecnologí, INIA, Madrid, Spain \\ ${ }^{2}$ Instituto de Virología, CICV, INTA-Castelar, Buenos Aires, Argentina \\ ${ }^{3}$ Departamento de Biología de Organismos y Sistemas, Instituto Universitario \\ de Biotecnología de Asturias (CSIC), Universidad de Oviedo, Oviedo, Spain
}

Accepted March 7, 2000

Summary. Transgenic plants represent an inexpensive alternative to classical fermentation systems for production of recombinant subunit vaccines. Transgenic potato plants were created that express the $\mathrm{N}$-terminal domain of the glycoprotein $\mathrm{S}(\mathrm{N}-\mathrm{gS})$ from Transmissible gastroenteritis coronavirus (TGEV), containing the major antigenic sites of the protein. Extracts from potato tubers expressing N$\mathrm{gS}$ were inoculated intraperitoneally to mice, and the vaccinated mice developed serum IgG specific for TGEV. Furthermore, when potato tubers expressing N-gS were fed directly to mice, they developed serum antibodies specific for gS protein, demonstrating the oral immunogenicity of the plant derived spike protein from TGEV.

$*$

Transmissible gastroenteritis coronavirus (TGEV) is the causative agent of acute diarrhea of newborn piglets that provokes high rate mortalities in affected farms. Protective immunity against this disease has to be developed in pregnant sows in order to confer passive protection to the piglets trough colostrum and milk. Neutralizing antibodies against the virus are directed mainly to glycoprotein $S$ $[12,15]$, and relevant epitopes in neutralization have been mapped into the $\mathrm{N}$ terminal domain of this protein [8]. Four major antigenic sites have been described in the globular part of glycoprotein $\mathrm{S}(\mathrm{gS})$, of which site $\mathrm{A}$ is the immunodominant [9-11, 21].

The protection of suckling piglets against an enteric TGEV infection is based on the uptake of specific lactogenic antibodies, mainly of the IgA class, in the milk 
of TGEV-immune mothers [4]. Since the concept of vaccine production in transgenic plants was first introduced by Mason and co-workers in 1992 [16], the oral immunogenicity of several antigens derived from human and animal pathogens expressed in transgenic plants have been demonstrated [1, 14, 17, 22, 24]. Oral immunization by edible vaccines produced in transgenic plants could stimulate immune responses at the portal entrance of many pathogens, facilitating the design of large-scale immunization programs. The $\mathrm{gS}$ from TGEV is an excellent model for developing oral vaccines against enteric pathogens of mammals because of its immunogenicity and resistance to degradation in the gut. Here, we report the expression of recombinant $\mathrm{N}$-terminal domain of $\mathrm{gS}(\mathrm{N}-\mathrm{gS})$ from $\mathrm{TGEV}$ in potato tubers and, more importantly, we demonstrate that transgenic potato tubers fed directly to mice stimulate the systemic production of antibodies against gS. These results contribute to support the feasibility of developing edible vaccines using as vectors transgenic plants expressing immunodominant antigens.

The plant expression vector pRoK I (Fig. 1A), derived from pRoK2 plasmid [2], containing the $\mathrm{N}$-terminal domain encoding sequence from $\mathrm{gS}$, and previously used to transform arabidopsis plants [13], was used to transform potato plants (Solanum tuberosum cv. Desirée), as previously described [7]. Briefly, leaf explants from 4-week-old potato plants were infected with recombinant $A$. tumefaciens (strain LBA4404). The inoculated leaves were blotted dry and placed on solidified shoot-promoting Murashige and Skoog medium [19] supplemented with $30 \mathrm{~g}$ of glucose per liter, $6 \mu \mathrm{M}$ zeatin riboside, and $0.02 \mu \mathrm{M}$ naphthalenacetic acid (CM medium). After 2 days of cocultivation, the plants were placed on CM medium supplemented with $300 \mathrm{mg}$ of ticarcillin and $100 \mathrm{mg}$ of kanamycin per liter (CMKT medium). After 3 to 4 weeks, regenerants appeared on CMKT medium at a frequency of 55\%. Each leave explant usually gave rise to four or five shoots. Regenerated shoots were subcultured and rooted on selective MS medium supplemented with $10 \mathrm{~g}$ of sucrose and $50 \mathrm{mg}$ of kanamycin per liter. The putative transgenic plants were transferred to a sterile peat-perlite (2:1) mixture and incubated in a growth chamber under normal humidity and light conditions. Fifteen different transformed potato clones were obtained by this methodology.

The presence of the N-gS gene in rooted plants was investigated by polymerase chain reaction (PCR). The DNA from fresh leaves, obtained as described elsewhere [13], was amplified (1389 bp fragment of $\mathrm{gS}$ ) by using a forward primer, 5'-GCGCGGATCCATGAAAAACTATTTGTGG-3', and a reverse primer, 5'GCGCGGTACCCGATGTGAAGCTATTG-3'. All independent transgenic potato plant lines were positive when screened for the presence of the recombinant gene by PCR analysis. Agarose electrophoresis analysis of the amplified products consistently showed the presence of the expected band of 1389 bp (Fig. 1B) in all putative $\mathrm{N}-\mathrm{gS}$ transgenic lines. No amplification product was obtained in $\mathrm{N}$-gS-unrelated transformed lines derived from vector pRoK2 or in wild-type potato.

The presence of the recombinant polypeptide in the plants harboring the foreign sequence was investigated by ELISA and Western blotting using an anti-TGEV polyclonal serum. Proteins from potato tubers were obtained by 

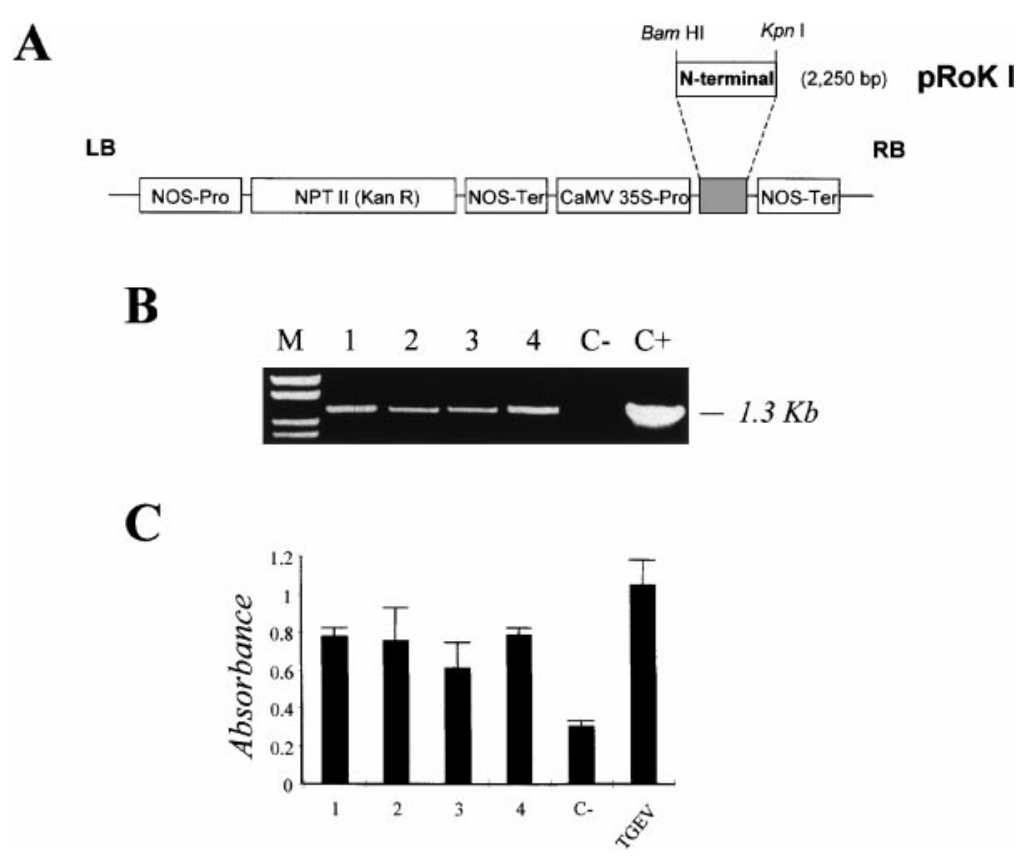

Fig. 1. Characterization of transgenic potato plants. A Schematic structure of the binary plasmid pRoK I used for Agrobacterium-mediated plant transformation. The DNA sequence encoding for the N-terminal domain of glycoprotein S from TGEV was cloned downstream of the CaMV 35S promoter in recombinant pRoK2 plasmid, followed by the nopaline synthase (NOS) terminator. This plasmid contains the left $(L B)$ and right $(R B)$ borders of transferred DNA that demarcates the sequences that are incorporated into the plant genome. B Presence of the recombinant sequence in representative transgenic potato plants detected by PCR. Plants 1 to 4 transformed with pRoK I, C- with pRoK2. $C$ represents the control amplification of the same DNA fragment from pRoK I. C Detection of N-terminal domain of glycoprotein S polypeptide in protein extracts from transgenic plants by ELISA. Absorbance readings were obtained from arabidopsis leaves extracts transformed with pRoK I (1 to 4). Positive control is purified virus (TGEV) and negative control is a plant transformed with pRoK2 plasmid $(C-)$. Bars represent the meaning of three independent experiments with standard deviations

homogenization of tubers in a blender with liquid nitrogen, and the resulting powder was resuspended in buffer $(0.3 \mathrm{~g}$ of fresh $\mathrm{wt} / \mathrm{ml})$ containing $10 \mathrm{mM} 2-(\mathrm{N}-$ morpholino)ethanesulfonic acid (MES), pH 6, $10 \mathrm{mM} \mathrm{NaCl}, 5 \mathrm{mM}$ EDTA, 0.6\% Triton X-100, $0.25 \mathrm{M}$ sucrose, $0.15 \mathrm{mM}$ spermine, $0.5 \mathrm{mM}$ spermidine, $10 \mathrm{mM}$ DTT, and $1 \mathrm{mM}$ phenylmethylsulfonyl fluoride. The extract was filtered and centrifuged $10 \mathrm{~min}$ at $12,000 \mathrm{~g}$, and the resulting supernatant was used for $\mathrm{N}-\mathrm{gS}$ polypeptide expression analyses. ELISA assay for detection of $\mathrm{N}-\mathrm{gS}$ polypeptide in plant extracts was carried out essentially as previously described [13], using to coat the plates a mixture of two monoclonal antibodies, 6AC3 and 8DH8 (kindly provided by Dr L. Enjuanes, Centro Nacional de Biotecnología, CSIC, Spain), recognizing the antigenic sites $\mathrm{A}$ and $\mathrm{D}$ of the gS, respectively [8]. Results demonstrated that potato tuber extracts from all analyzed plants were positive on ELISA (Fig. 1C). An experiment performed to quantify the expression of recombinant 
$\mathrm{gS}$ protein expression in the potato tubers, using purified TGEV and different concentrations of transgenic plant extracts in ELISA [13], showed similar levels of expression in potato tubers that those found in transgenic arabidopsis $(0.02$ $0.07 \%$ of total soluble tuber protein). Western blot analyses of the plant extracts with anti-gS antibodies revealed no specific reactions with any protein (data not shown). It could be due to the low levels of recombinant protein expression and to the conformational nature of most of the immunodominant epitopes present in this protein.

Tubers from transgenic potato plants expressing $\mathrm{N}-\mathrm{gS}$ were used to immunize mice. Adult (60 to 90 days old) male BALB/c mice were immunized intraperitoneally on days $0,15,30$ and 45 with either potato extracts from transgenic plants expressing $\mathrm{N}-\mathrm{gS}$ or potato plants transformed with pRoK2 plasmid (150 $\mu \mathrm{g}$ of potato extract in incomplete Freund's adjuvant per animal per injection). Ten days after the last booster, mice sera (different dilutions in PBS-Tween 20) were evaluated for anti-gS-specific antibodies by ELISA using purified TGEV $(0.2 \mu \mathrm{g})$ as antigen. A goat anti-mouse antibodies (1:500) was used to reveal immunocomplexes. Figure $2 \mathrm{~A}$ shows that all sera reacted with the virus showing, as expected, different titers.

To determine oral immunogenicity of the recombinant protein, BALB/c mice were fed with potato tubers expressing $\mathrm{N}-\mathrm{gS}$ (3 times per week with $2 \mathrm{~g}$ of transgenic potato tuber during a two months period). Sera from these animals were analyzed by ELISA, showing an specific antibody response against the plantderived $\mathrm{gS}$, indicating the oral immunogenicity of the expressed protein (Fig. 2B). As expected, no antibody response against $\mathrm{gS}$ was detected in mice fed with potato tubers expressing an unrelated gene (VP1 of foot and mouth disease virus).

The specificity of sera reactivity in ELISA with the virus-induced protein was confirmed by immunoprecipitation of the ${ }^{35} \mathrm{~S}$-methionine labeled gS expressed by a recombinant vaccinia virus. Immunoprecipitation of glycoprotein $\mathrm{S}$ by sera from mice orally immunized was essentially carried out as previously described for mouse antibodies [5, 13], using CV1-infected cells with a recombinant vaccinia virus expressing the gS (Gómez and Escribano, unpubl. res.). Infected cells were pulse labeled at $14 \mathrm{~h}$ post infection for $2 \mathrm{~h}$ with $200 \mu \mathrm{Ci} / \mathrm{ml}$ of ${ }^{35} \mathrm{~S}$-methionine $(800 \mathrm{Ci} / \mathrm{mmol}$; Amersham International, Amersham, England), and lysed before immunoprecipitation with lysis buffer [13]. The antigen-antibody complexes were analyzed in 7.5\% SDS-PAGE. All sera from mice fed with transgenic potatoes expressing N-gS immunoprecipitated the vaccinia virus-induced $\mathrm{gS}$, confirming the specificity of ELISA results obtained with purified TGEV (Fig. 2C). An immunoblotting analysis of these sera using the vaccinia expressed $\mathrm{gS}$ or the TGEV-induced $\mathrm{gS}$ transferred to the nitrocellulose strips did not show positive reaction. It suggests a reduced sensitivity of immunoblotting technique in this case to respect to ELISA or immunoprecipitation, in which the protein is in native condition. Finally, an in vitro seroneutralization assay of TGEV by sera from mice immunized either intraperitoneally or orally with potato tuber extracts did not render significant neutralization values of the virus (data not shown). 

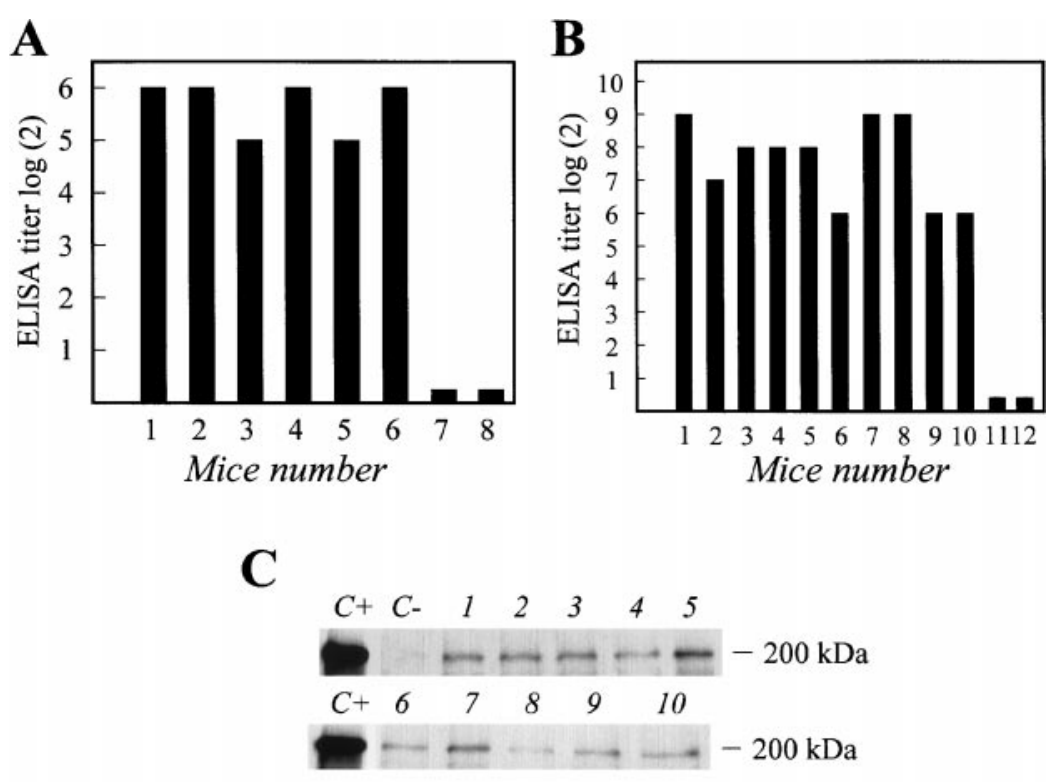

Fig. 2. Antibody responses to the plant-derived N-terminal domain of glycoprotein $S$ polypeptide in immunized mice. A ELISA titers of sera from mice inoculated intraperitoneally with potato tuber extracts expressing the $\mathrm{N}$-terminal domain of glycoprotein $\mathrm{S}$ (mice 1 to 6), using purified TGEV as antigen. Mice 7 and 8 represent ELISA titers of two mice immunized with a pRoK 2 transformed plant extract. B ELISA titers of sera from orally immunized mice with transgenic potato tubers expressing the N-terminal domain of glycoprotein $S$ (mice 1 to 10). Mice 11 and 12 represent ELISA titers of two mice immunized orally with a pRoKVP1 transformed potato, expressing VP1 protein from foot and mouth disease virus. C Immunoprecipitation of glycoprotein $S$ expressed by a recombinant vaccinia virus by antibodies present in sera from orally immunized mice with potato tubers expressing the N-terminal domain of the glycoprotein S. A pool of specific monoclonal antibodies was used as a control positive serum $(C+)$ and a serum from a mouse immunized with potato tubers transformed with pRoKVP1 (serum 11) was used as a negative control $(C-)$

The results presented here demonstrate the feasibility of expressing the $\mathrm{N}$ terminal domain of glycoprotein $\mathrm{S}$ in potato plants. However, when the gene encoding the complete $\mathrm{gS}$ was used to transform potato plants, only a few transgenic lines were obtained presenting reduced growth rates compared to control plants or plants transformed with the sequence encoding the N-gS. Therefore, we selected the plants expressing the $\mathrm{N}-\mathrm{gS}$ for further analyses, specially because this protein domain contains the four major antigenic sites of $\mathrm{gS}$ [9-11, 21]. The selected transgenic plants showed expression levels similar to that described with equivalent constructs in arabidopsis plants [13], and those found expressing hepatitis B surface antigen, rabies virus glycoprotein or VP1 from foot and mouth disease virus $[6,16,18]$. The demonstration that many proteins from pathogens, including some expressed in transgenic plants [14, 17, 24], are immunogenic when administered orally, encourage the study of other antigens expressed in plants with the goal of developing edible vaccines. Glycoprotein $\mathrm{S}$ 
from TGEV is an interesting model since this protein is resistant, at least when incorporated into the viral particle, to the gut degradation. In addition, the protective immune responses against TGEV have to be stimulated at the mucosal surfaces in order to elicit secretory and lactogenic immunity [9, 10, 20, 23]. In the above described work, we have demonstrated that the N-terminal domain of glycoprotein $\mathrm{S}$ expressed in potato plants is immunogenic when mice were fed with the transgenic potato tubers. Antibody titers obtained in mice orally immunized were higher than those obtained after intraperitoneal immunization. It could be explained by the differences in the antigen doses used in each administration route. Unfortunately, we were unable to induce neutralizing antibodies with the potato-derived gS independently of the immunization route used. Interestingly, in a similar experiment performed previously, all mice intramuscularly immunized with arabidopsis-derived $\mathrm{gS}$ presented a significant neutralization activity in their sera [13]. The differences in neutralization activity between sera from mice immunized with the arabidopsis-derived $\mathrm{gS}$ and potato-derived $\mathrm{gS}$ could be influenced by the postranslational processing of the glycoprotein depending of the plant used, or due to the plant proteins that, accompanying the recombinant $\mathrm{gS}$, differentially modify in each plant species its spatial structure.

Interestingly, in these experiments we have observed that a long protocol of oral immunization, using transgenic plants as antigen delivery vector, regularly elicited a significant immune response to the recombinant antigen, even when it is expressed at low levels. Similar results were previously obtained by our group using the structural protein VP1 from foot and mouth disease virus expressed in transgenic alfalfa [24] and agree with reports from others using transgenic plants as edible vaccines $[1,14,17,22]$. In all these cases, as well as it happens with the oral administration of the plant-derived $\mathrm{N}-\mathrm{gS}$, no immunotolerance was established in any of the vaccinated individuals. This observation is very important in case of evaluating, in the future, the feasibility of vaccinating farm animals through the diet. These results, also, make reasonable to extend similar immunological studies to the natural host, the swine, in order to test the lactogenic immunity conferred to suckling piglets by feeding pregnant sows with the plant-derived $\mathrm{gS}$.

\section{References}

1. Arakawa I, Chong DKX, Langridge WHR (1998) Efficacy of a food plant-based oral cholera toxin B subunit vaccine. Nat Biotech 16: 292-297

2. Baulcombe DC, Saunders GR, Bevan MW, Mayo MA, Harrison BD (1986) Expression of biologically active viral satelite RNA from nuclear genome of transformed plants. Nature 321: 446-449

3. Bechtold N, Ellis J, Pelletier G (1993) Agrobacterium mediated gene transfer by infiltration of adult Arabidopsis thaliana plants. C R Acad Sci Paris 316: 1 194-1 199

4. Bohl EH (1981) Transmissible gastroenteritis. In: Leman AD, Glock RD, Mengeling WL, Penny RHC, School E, Straw B (eds) Diseases of swine. Iowa State University Press, Ames, pp 195-208

5. Bullido R, Alonso F, Gómez del Moral M, Ezquerra A, Alvarez B, Ortuño E, Dominguez $\mathrm{J}$ (1996) Monoclonal antibody $2 \mathrm{~F} 4 / 11$ recognizes the $\alpha$ chain of the porcine $\beta_{2}$ integrin 
involved in adhesion and complement mediated phagocytosis. J Immunol Methods 195: $125-134$

6. Carrillo C, Wigdorovitz A, Oliveros JC, Zamorano PI, Sadir AM, Gómez N, Salinas J, Escribano JM, Borca MV (1998) Protective immune response to foot-and-mouth disease virus with VP1 expressed in transgenic plants. J Virol 72: 1688-1 690

7. Castañón S, Marín MS, Martín-Alonso JM, Boga JA, Casals R, Humara JM, Ordás RJ, Parra F (1999) Immunization with potato plants expressing VP6O protein protects against Rabbit hemorrhagic disease virus. J Virol 73: 4 452-4 455

8. Correa I, Jiménez G, Suñé C, Bullido MJ, Enjuanes L (1988) Antigenic structure of E2-glycoprotein of transmissible gastroenteritis coronavirus. Virus Res 10: 77-94

9. De Diego M, Laviada MD, Enjuanes L, Escribano JM (1992) Epitope specificity of protective lactogenic immunity against swine transmissible gastroenteritis virus. J Virol 66: 6502-6508

10. De Diego M, Rodríguez F, Alcaraz C, Gómez N, Alonso C, Escribano JM (1994) Characterization of the IgA and subclass IgG responses to neutralizing epitopes after infection of pregnant sows with the transmissible gastroenteritis virus or the antigenically related porcine respiratory coronavirus. J Gen Virol 75: 2 585-2 593

11. Delmas B, Rasschaert D, Godet M, Gelfi J, Laude H (1990) Four major antigenic sites of the coronavirus transmissible gastroenteritis virus are located on the amino-terminal half of spike glycoprotein S J Gen Virol 71: 1313-1 323

12. Garwes DJ, Lucas MH, Higgins DA, Pike BV, Cartwright SF (1978) Antigenicity of structural components from porcine transmissible gastroenteritis virus. Vet Microbiol 3: $179-190$

13. Gómez N, Carrillo C, Salinas J, Parra F, Borca MV, Escribano JM (1998) Expression of immunogenic glycoprotein $\mathrm{S}$ polypeptides from Transmissible gastroenteritis coronavirus in transgenic plants. Virology 249: 352-358

14. Haq TA, Mason HS, Clements JD, Arntzen CJ (1995) Oral immunization with a recombinant bacterial antigen produced in transgenic plants. Science 268: 714-716

15. Jiménez G, Correa I, Melgosa MP, Bullido MJ, Enjuanes L (1986) Critical epitopes in transmissible gastroenteritis virus neutralization. J Virol 60: 131-139

16. Mason HS, Lam DM-K, Arntzen CJ (1992) Expression of hepatitis B surface antigen in transgenic plants. Proc Natl Acad Sci USA 89: 11 745-11 749

17. Mason, HS, Bali JM, Shi J-J, Jiang X, Estes MK, Arntzen CJ (1996) Expression of Norwalk virus capsid protein in transgenic tobacco and potato and its oral immunogenicity in mice. Proc Natl Acad Sci USA 93: 5335-5 340

18. McGarvey PB, Hammond J, Dienelt MM, Hooper DC, Fu ZF, Dietzschold B, Koprowski H, Michaels FH (1995) Expression of the rabies virus glycoprotein in transgenic tomatoes. Biotechnology 13: 1484-1 487

19. Murashige T, Skoog F (1962) A revised medium for rapid growth and bioassays with tobacco tissue cultures. Physiol Plant 15: 473-497

20. Saif LJ, Bohl EH (1979) Passive immunity in transmissible gastroenteritis of swine: immunoglobulin classes of milk antibodies after oral-intranasal inoculation of sows with a live low cell culture-passaged virus. Am J Vet Res 40: 115-117

21. Sánchez CM, Jiménez G, Laviada MD, Correa I, Suñé C, Bullido MJ, Gebauer F, Smerdou C, Callebau P, Escribano JM, Enjuanes L (1990) Antigenic homology among coronaviruses related to transmissible gastroenteritis virus. Virology 174: 410-417

22. Tacket CO, Mason HS, Losonsky G, Clements JD, Levine MM, Arntzen CJ (1998) Immunogenicity in humans of a recombinant bacterial antigen delivered in a transgenic potato. Nat Med 4: 607-609 
23. Wesley RD, Woods RD, Correa I, Enjuanes L (1988) Lack of protection in vivo with neutralizing monoclonal antibodies to transmissible gastroenteritis virus. Vet Microbiol 18: 197-203

24. Wigdorovitz A, Carrillo C, Dus Santos MJ, Trono K, Peralta A, Gómez MC, Ríos RD, Franzone PM, Sadir AM, Escribano JM, Borca MV (1999) Induction of a protective antibody response to foot and mouth disease virus in mice following oral or parental immunization with alfalfa transgenic plants expressing the viral structural protein VP1. Virology 255: 347-353

Authors' address: Dr. J. M. Escribano, Dipto. de Mejora Genética y Biotecnología, INIA, Ctra de la Coruña, Km 7, E-28040 Madrid, Spain.

Received January 19, 2000 